\title{
Relações Brasil-Argentina: a cooperação cultural como instrumento de integração regional
}

\section{Brazil-Argentina relations: cultural cooperation as an instrument for regional integration}

Raquel Paz dos Santos

Ojalá que la aproximación cultural americana, uno de los acontecimientos más importantes de los últimos tiempos, sirva en su esfera para ofrecer a la Europa desgarrada la muestra de lo que es posible conseguir con buena voluntad y el trato sin orgullo entre los hombres de unos y otros países.

César Viale

Raquel Paz dos Santos é professora visitante do Programa de Pós-Graduação em História Comparada (PPGHC) e Coordenadora do Laboratório de Estudos Brasil na América do Sul (LEBAS), vinculado ao Laboratório de Estudos Tempo Presente do Instituto de Filosofia e Ciências Sociais da UFRJ, Rio de Janeiro, Brasil (raquelpazdossantos@terra.com.br).

Artigo recebido em 30 de junho de 2009 e aprovado para publicação em $1^{\circ}$ de outubro de 2009.

Est. Hist., Rio de Faneiro, vol. 22, n. 44, p. 355-375, julho-dezembro de 2009. 


\section{A cultura como via para uma nova reflexão historiográfica sobre as relações bilaterais}

Tomando a cultura como um elemento de cooperação que, consequentemente, favorece uma maior aproximação e entendimento entre os países, este estudo busca desenvolver uma análise das relações culturais entre Brasil e Argentina durante os anos de 1930 a 1954. Propõe assim uma nova diretriz interpretativa da história dessas relações ao afastar-se do tradicional paradigma realista ${ }^{1}$ e apoiar-se nas recentes reflexões teóricas relacionadas ao construtivismo ${ }^{2}$ e às relações culturais internacionais.

Como assinala César Viale (1945: 16), presidente do Instituto Argentino-Brasileño de Cultura de Buenos Aires, a importância da aproximação cultural americana transcendia as relações bilaterais e fazia parte de um projeto mais amplo de aproximação cultural dos países do continente, em oposição à suposta "superioridade" das culturas europeias. Buscava-se a legitimação de uma nova estética, referendando os projetos de desenvolvimento nacional, que apoiavam a perspectiva de uma integração regional em busca de uma maior autonomia econômica da América Latina frente às grandes potências.

No decorrer do período aludido, houve momentos de forte aproximação política e econômica entre os dois países. Assim, visando a consolidar esses vínculos, promoveu-se um expressivo intercâmbio entre as duas sociedades, através da diplomacia cultural e de diversos setores da sociedade civil.

Para analisar o vasto universo dessas relações, utilizo a documentação referente às missões científicas e artísticas, às exposições de arte e de literatura, às traduções de livros de escritores argentinos e brasileiros para o português e o espanhol, às mostras de livros e de turismo, aos institutos culturais, às escolas "argentinas" e "brasileiras" - que procuraram estimular o sentimento de fraternidade bilateral e continental -, aos intercâmbios sindicais etc. Esses diferentes "embaixadores" das culturas argentina e brasileira no país vizinho, independentemente de suas filiações ideológicas, estiveram imbuídos do ideário americanista de valorização das raízes culturais latino-americanas e permaneceram convictos de que a cooperação entre os dois países contribuiria para o progresso e o desenvolvimento mútuos.

Por isso, na concepção de certos setores governamentais, grupos econômicos e intelectuais, tornou-se fundamental substituir o paradigma da rivalidade pelo da cooperação. Na realidade, esses dois paradigmas caminharam juntos, ao longo das décadas de 1930 e 50, evidenciando toda a complexidade dessas relações.

A maior parte desses projetos culturais foi patrocinada pelo Estado, contando, em alguns momentos, com o apoio da iniciativa privada, como bancos, 
setores da imprensa e do comércio etc. Nesses casos, a diplomacia e os órgãos pertencentes ou que tinham algum tipo de financiamento governamental como os institutos culturais, as academias de Medicina, História e Belas Artes, os museus históricos, os museus nacionais de Belas Artes, as bibliotecas nacionais, as universidades e escolas públicas etc. - desenvolveram suas ações culturais no país vizinho, tendo, geralmente, o apoio das embaixadas e permanecendo em consonância com os interesses estatais.

Entretanto, isso não pode ser visto como uma regra, pois muitos desses grupos, como os intelectuais, valeram-se dos recursos públicos para difundir e publicar seus estudos no país vizinho, independentemente de qualquer convergência com as políticas governamentais. Os médicos argentinos e brasileiros promoveram a cooperação bilateral mais intensa desse período, aproveitando ocasiões como congressos, palestras e missões científicas para intercambiar conhecimentos de sua área profissional. Assim, não estavam, obrigatoriamente, preocupados com os interesses políticos e econômicos que justificavam os significativos investimentos de seus governos no fomento da cooperação cultural. Vale ressaltar que diversos desses agentes culturais realizaram uma ação espontânea na sociedade vizinha.

Dessa forma, o presente estudo faz duas contundentes críticas ao paradigma realista, que influenciou consideravelmente a historiografia das relações argentino-brasileiras. Primeiramente, evidencia que o Estado não atua de forma exclusiva nas relações internacionais. O complexo trânsito simbólico entre as duas sociedades demonstrou que vários grupos sociais tiveram uma atuação expressiva na cooperação cultural. Uma segunda crítica se refere ao fato de que o estudo das relações culturais entre os dois países revelou novas dimensões da realidade não contempladas pela análise realista. Ao valorizar apenas os aspectos políticos e econômicos, na perspectiva de uma permanente disputa geopolítica, tal análise não foi capaz de identificar os processos de cooperação entre os dois países.

\section{A diplomacia cultural como uma nova diretriz interpretativa das relações bilaterais}

Os fatores que impulsionaram a aproximação do Brasil com os países da região estão relacionados à crise do liberalismo e do capitalismo nos anos 1930. Diante da fragilidade de suas economias agroexportadoras, seus governos perceberam a necessidade de estabelecer uma relação de cooperação mútua para superarem suas dificuldades econômicas. Nesse momento a América Latina passou a reivindicar um modelo próprio de desenvolvimento, associado ao projeto de integração econômica, no qual Argentina e Brasil foram vistos como importantes 
lideranças no continente sul-americano. Além disso, foi crescente a complementaridade entre suas economias.

Amado Luis Cervo (2001: 23-61) assinala também que essa nova conjuntura provocou uma mudança no posicionamento externo dos Estados latino-americanos, passando a implementar profundas reformas em suas chancelarias, gerando uma nova concepção de diplomacia que Cervo define como "desenvolvimentista". Segundo o autor, no período compreendido entre os anos 1930-1947, observou-se o abandono do paradigma "liberal conservador" e o esboço do "Estado desenvolvimentista". Os efeitos da crise capitalista de 1929 teriam estimulado o processo de modernização econômica da região, que passou a ter uma grande intervenção estatal para superação de suas dificuldades e promoção do seu desenvolvimento. Nesse contexto, toda a estrutura administrativa foi reformada para se tornar mais eficiente e se adequar às novas necessidades de seu país. Dessa forma, a estrutura dos Ministérios das Relações Exteriores passou por uma série de transformações, objetivando maior profissionalização e vinculação da diplomacia às metas definidas pelo Estado.

Além dessas transformações, a política externa dos governos da região também foi influenciada pela emergência do tema cultural. Nos anos 1920, a Sociedade das Nações defendia que, para se evitar um novo conflito entre os países, era necessário não apenas ampliar a cooperação política e econômica entre eles, mas também estimular o conhecimento da história e da cultura dos países vizinhos, contribuindo assim para desfazer visões distorcidas ou preconceituosas. Tal fato estimularia a boa convivência e o relacionamento pacífico entre os povos. Em função disso, a cultura passou a fazer parte da agenda internacional a partir dos anos 1930. Nesse sentido, as reformas desenvolvidas no Itamaraty pelo governo Vargas foram de fundamental importância para imprimir essa nova vertente na política externa, pois difundir as "coisas brasileiras" em nível internacional fazia parte de seu projeto nacionalista. ${ }^{3}$

O ponto inicial da cooperação cultural entre os dois países foram os acordos e convênios entre os presidentes Augustín Justo e Getúlio Vargas, firmados entre as visitas presidenciais de 1933 e 1935. Rosendo Fraga enumera seu conteúdo:

Diez de estos acuerdos se refieren a temas económicos y comerciales. Se tratan asuntos como navegación marítima y aérea, el tránsito, el turismo, el comercio de productos concretos, la cooperación en productos comunes como la yerba mate, las medidas de sanidad vegetal, etc. Los temas políticos están presentes en cuatro tratados, dos referidos a extradición, otro a las luchas civiles y sus repercusiones en los respectivos países (...) un intento de integración en el campo educativo y cultural (...). Los cinco tratados referidos a esta área así 
lo demuestran, estos son: convenio de intercambio artístico, revisión de los textos de enseñanza de historia y geografía y el intercambio de profesores y alumnos. (Fraga, 2000: 419)

Esses tratados bilaterais representaram um divisor de águas nas relações argentino-brasileiras, até então predominantemente caracterizadas por atritos políticos e econômicos que fomentavam a imagem da rivalidade. Em seu diário, Vargas fez anotações sobre sua visita à Argentina, que evidenciavam essa nova fase de suas relações:

Nossos militares apreciaram as demonstrações de apreço que receberam de seus colegas (...) onde esperavam encontrar desconfianças e restrições por certas intrigas desnecessárias (...) a visita teve um grande efeito político de aproximação, de conhecimento recíproco e de melhor compreensão. Para simpatizar é preciso compreender. (Vargas, 1935)

"Para simpatizar é preciso compreender" foi um princípio importante no direcionamento dos projetos de intercâmbio artístico e intelectual com a Argentina que tiveram início no governo Vargas, e é muito significativo para a compreensão do papel dos embaixadores e intelectuais de ambos os países durante esse período. Essa política também foi estendida aos países vizinhos, permitindo a adesão aos convênios e acordos culturais assinados entre Justo e o presidente brasileiro. ${ }^{4}$ Obviamente, tal política estava relacionada a interesses econômicos e políticos na região, mas eles não a esgotam.

Ambos os encontros tiveram, como horizonte, as conferências americanas internacionais que se realizariam imediatamente depois, frente às quais os dois governos adotaram posições comuns. Justo visitou o Rio de Janeiro duas semanas antes da VII Conferência Interamericana de Montevidéu, no ano de 1933. Quando Vargas foi a Buenos Aires, em 1935, a capital argentina sediava a Conferência Pan-Americana de Comércio. Posteriormente, esses acordos e convênios foram ratificados, e outros, da mesma natureza, foram assinados ao longo dos anos 1940 e 60. Além disso, toda uma estrutura foi montada - como a criação de instituições para difusão cultural no exterior, convocação e seleção de intelectuais e especialistas em diversas áreas para promoção do intercâmbio, liberação de recursos financeiros etc. - pelos governos de ambos os países, para viabilizar e executar diferentes projetos de cooperação cultural.

Em tal conjuntura, o discurso anti-imperialista teve grande eco entre vários setores das classes dominantes e intelectuais da América Latina. O im- 
perialismo, sobretudo o norte-americano, foi alvo de inúmeras críticas por parte de grupos de diferentes tendências ideológicas - conservadores, reformistas, progressistas e revolucionários. Todos esses segmentos políticos elaboraram distintos projetos para a superação dos graves problemas políticos, econômicos e sociais de seus países, articulando a promoção do desenvolvimento regional com o chamado "continentalismo".

No âmbito cultural, esse ideário americanista pautou-se na valorização das raízes culturais latino-americanas, visando à afirmação de uma nova estética, na qual a "mestiçagem", típica dos povos da região, deixaria de ser símbolo de "inferioridade racial" de países supostamente incapazes de alcançar a civilização e o progresso, como condenavam as teorias racistas europeias. Dessa forma, percebe-se que, para que a América Latina emergisse no cenário internacional como desenvolvida e moderna, seria fundamental a construção de uma nova identidade cultural. Essa última deveria romper com as visões estigmatizadas e preconceituosas da região. Num contexto de maior cooperação entre os seus países, o intercâmbio artístico e intelectual passou a ser concebido como um fator importante em prol do desenvolvimento comum, do conhecimento mútuo, o que consolidou vínculos comerciais e políticos.

Mesmo diante dessa nova postura, a cooperação política, econômica ou cultural com os Estados Unidos não foi de forma alguma excluída pelos governos e setores interessados em reformas. Procurou-se intensificá-la, mas a partir de novas bases. Ou seja, romper com a tradicional subserviência da região aos interesses norte-americanos, a fim de propor formas de cooperação, sobretudo comerciais e tecnológicas, que contribuíssem para o crescimento e o progresso da América Latina.

Um exemplo desse posicionamento foi a política externa adotada pelo governo brasileiro. Dos anos 1930 até a entrada no esforço de guerra em 1942, o Brasil desenvolveu um processo de barganha pendular, entre as perspectivas de alinhamento com a Alemanha ou com os EUA, obtendo enormes benefícios para seu comércio exterior e industrialização, caracterizando o que Gerson Moura (1980: 56) definiu como equidistância pragmática. Sua posterior opção por apoiar o governo norte-americano não estava desassociada dos interesses nacionais, pois trouxe grandes benefícios para o país, com a implantação da Companhia Siderúrgica Nacional em 1943, o maior complexo siderúrgico da América Latina, e a equiparação e treinamento das Forças Armadas. Contudo, não se desvinculou de sua política regional.

Na década de 1940, o convite feito pelo Itamaraty a Gilberto Freyre para elaborar a política cultural do Brasil para a América delineou aspectos importantes dessa vertente. Ao defender a integração do continente, Freyre declarava-se completamente oposto à concepção de uma homogeneidade cultural que, a seu 
ver, apenas geraria conflitos entre as diferentes culturas americanas. Assim, segundo ele, era necessário "combinar a unidade com a variedade" (Freyre, 2003: 47). Assinalava ainda que, diante da similitude dos graves problemas enfrentados, e ainda sem solução, tornava-se imprescindível o desenvolvimento de esforços de cooperação interamericana no estudo e no trato dessas questões, o que contribuiria para uma maior aproximação entre os povos das Américas.

Embora considerasse ou enfatizasse o regional - e aí a América tropical ou meridional era o território considerado -, não deixava de incluir os EUA e outros países da América anglo-saxã em sua concepção de política hemisférica ou interamericana. $\mathrm{O}$ que pretendia era sublinhar as diferenças, a diversidade, em oposição ao projeto de "americanização" pretendido pelos Estados Unidos. Contudo, ressaltava que esse estudo comum deveria ser "simpático, e não frio, sem amor, das diferenças. O estudo da maneira de conciliá-las sem esmagá-las, tanto depende delas a verdadeira saúde social e de cultura do continente" (Freyre, 2003: 51).

Ao analisar as representações estadunidenses que se opunham às visões preconceituosas em relação à América Latina, Ricardo Salvatore (2006: 143-168) assinala que, em alguns casos, a mescla racial assumia uma conotação positiva - ao contrário do discurso que dominara a primeira fase imperialista dos Estados Unidos que, para justificar os atrasos e carências da América Latina, utilizava, como argumentos, a instabilidade política das novas repúblicas e a mestiçagem da população. A industrialização e a expansão dos mercados para produtos norte-americanos na América do Sul contribuíram para uma visão otimista das relações raciais. Nesse contexto, o Brasil chegou a ser visto como um país que experimentava uma singular "democracia racial", que o assemelhava a um crizol de razas (Salvatore, 2006: 156) - uma concepção estabelecida por Freyre na década de 1930.

Nesse contexto, escritores norte-americanos que criticavam as políticas de intervenção de seu país ressaltaram a necessidade de maiores conhecimentos sobre o subcontinente. Um desses intelectuais foi o predicador, educador e historiador Samuel G. Inman, que escreveu influentes críticas às diretrizes da política externa dos EUA e propagou a ideia de que profundos mal-entendidos em torno das diferenças culturais entre latino-americanos e norte-americanos eram obstáculos para a melhoria das relações entre os povos.

As análises de Salvatore revelam a importância de matizar a questão do imperialismo norte-americano. Esse aspecto constitui um ponto relevante para o estudo aqui proposto, pois amplia os horizontes de compreensão das relações interamericanas entre os anos 1930 e 1954 para além do difundido discurso sobre o expansionismo estadunidense produzido pelos neomarxistas, teóricos da dependência e nacionalistas, que o definem como um "derrame", do centro à periferia, de mercadorias, capital, tecnologia, força militar, visando a reproduzir as 
relações de dominação e extração de mais-valia. $\mathrm{O}$ autor qualifica tal discurso como reducionista e economicista, afirmando que ele não valoriza o papel da cultura.

Retornando à análise conjuntural, a imposição da nova ordem mundial pós-Segunda Guerra, com a consolidação da hegemonia norte-americana no continente e a deflagração da Guerra Fria, levou a um enfraquecimento do poder de pressão e barganha da América Latina. Nesse momento, a grande maioria dos países alinhou-se aos Estados Unidos - entendendo que esta seria a melhor alternativa para dar prosseguimento ao desenvolvimento de suas economias -, passando a negociar isoladamente com a grande potência regional, produzindo um certo esvaziamento no ideário de integração latino-americana.

Diante desse quadro, o peronismo, em fins dos anos 1940 até meados dos anos 50, constituiu-se num importante foco de resistência às imposições dos EUA, tentando recuperar o seu poder de barganha internacional. Buscou-se também revigorar os projetos de integração regional, através da reformulação do Pacto ABC, que contou com o apoio de Carlos Ibáñez, presidente do Chile, e de Vargas, em seu segundo governo, de 1951 a 1954. Vale observar que esse momento se deu apesar de grande parte da classe dominante brasileira ser radicalmente contra uma aproximação com a Argentina de Juan Perón, preferindo um alinhamento irrestrito com a potência do norte.

No decorrer de suas duas presidências, entre 1946 e 1955, e especialmente ao longo de seu segundo mandato, de 1951 a 1955, o governo de Perón procurou desenvolver um contínuo intercâmbio cultural com os países latino-americanos, visando a difundir seu projeto político-ideológico expresso através da Terceira Posição. Sua adoção, em 1947, ocorreu em um contexto difícil para a América Latina, como anteriormente citado. Entretanto, o governo peronista insistia na necessidade de os países latino-americanos continuarem buscando uma maior autonomia frente aos dois blocos de poder então constituídos, não se aliando nem ao capitalismo nem ao comunismo, antecipando assim o movimento dos não-alinhados.

Nesse momento, setores aliados ao governo de Vargas procuraram intensificar as relações culturais com o país platino, pois concebiam que uma aliança do Brasil com a Argentina seria fundamental para possibilitar uma maior autonomia de suas economias. Entretanto, o fato de a UDN e os militares não terem o posicionamento ideológico de que a formação de um bloco econômico latino-americano poderia ser mais benéfica para a política externa do país do que a manutenção de um alinhamento dependente com os EUA contribuiu para o fracasso desse processo e impediu um desenvolvimento mais independente da região.

Mesmo diante do insucesso da proposta de integração econômica, é importante assinalar que houve significativos investimentos de ambos os governos 
na diplomacia cultural, pois nesse momento tornou-se premente desfazer visões distorcidas e antigos receios em relação ao país vizinho. Como exemplo, cito as referências ao tema na correspondência de João Batista Luzardo, embaixador em Buenos Aires de 1951 a 1954. Mensalmente, o Instituto Cultural Brasil-Argentina, órgão apoiado pela embaixada, emitia um amplo boletim das atividades culturais de intercâmbio artístico e intelectual, como mostras de cinema, exposições artísticas, exposição e venda de livros de autores brasileiros consagrados, missões intelectuais, visitas de professores e estudantes, inauguração de bibliotecas populares, entre outras.

\subsection{Letras, artes, educação e ciência: as diferentes faces do intercâmbio cultural}

Nesta parte destacarei as principais formas de intercâmbio intelectual e artístico entre Argentina e Brasil durante o período de 1930 a 1954 . A intensa difusão cultural proporcionou um maior conhecimento da outra sociedade, paralelo à construção de um imaginário em torno das ideias de cooperação, integração, respeito às diferenças e valorização da cultura nacional e latino-americana, visando à legitimação do projeto governamental.

Essas políticas de aproximação cultural contribuíram para a crítica de antigos estereótipos, preconceitos, desconfianças e outras imagens negativas pelas quais se estabeleceu o paradigma da rivalidade como um elemento intrínseco às relações argentino-brasileiras.

Nesse contexto, a busca por conhecer e interagir com a diversidade num esforço de compreensão da alteridade - constitui o elemento fundamental para o entendimento dessas relações culturais. A ampla circulação de pessoas entre os países, ocasionada pelos incentivos ao turismo, as caravanas de estudantes, professores, trabalhadores e artistas, as missões intelectuais, entre outros, contribuíram, em certa medida, para desmistificar o "outro", uma vez que se passava a conhecê-lo melhor.

Dessa forma, toda essa efervescência cultural levou à construção de uma empresa del conocimiento, na concepção de Salvatore (2006: 13), o que evidenciou o papel central do imaginário para a legitimação não apenas dos projetos nacionalistas, mas também do ideário em torno da integração da América Latina.

\section{a) O papel dos institutos culturais}

Nos anos 1930, institutos culturais foram fundados em Buenos Aires e no Rio de Janeiro, espalhando-se por outras cidades argentinas e brasileiras, como Rosário, Córdoba, Porto Alegre e São Paulo. Tal fato demarcou um novo momento de aproximação entre os dois países e, por sua vez, uma nova fase na história de suas relações. A dimensão cultural passou a fazer parte de ambas as 
agendas, sendo concebida como um elemento fundamental para a execução dos objetivos políticos e econômicos.

Entre as atribuições dos institutos, as principais eram representar, ante as autoridades competentes, a conveniência de acentuar nos ensinos geral, normal ou comercial um melhor conhecimento da geografia e da história do Brasil e da Argentina, desde a proclamação da República até o presente. $\mathrm{O}$ incentivo também se estendia ao ensino da língua e da literatura de ambos os países, além de outros estudos sobre sua produção científica, comercial e industrial. Para estimular o turismo, seria promovida a preparação de cursos breves de idioma e de vocabulário elementar para uso do viajante.

Uma característica relevante dos institutos culturais era o fato de gozarem de autonomia formal, reforçando a ideia de que os intelectuais que apoiaram a política externa dos governos brasileiro ou argentino em prol de uma aproximação cultural com o país vizinho não foram manipulados pelo Estado, mas apoiaram suas políticas nessa área porque tinham afinidades com as ideias que as regiam. Portanto, a adesão dos intelectuais a essa diretriz política foi espontânea e, por outro lado, também interessada, pois, através dela, poderiam obter os recursos financeiros e operacionais de que não dispunham para desenvolver seus projetos.

Os monumentos à fraternidade argentino-brasileira foi uma outra iniciativa cultural importante dos institutos para reforçar o sentimento de amizade e cooperação. Em Buenos Aires, um busto em homenagem a Tiradentes foi inaugurado em 1946. Em São Paulo, um busto de Bernadino Rivadavia foi criado em 1945, em homenagem ao centenário do seu nascimento.

Todas essas atividades desenvolvidas pelos institutos culturais, além da organização de congressos, seminários, concursos literários, de monografias e biografias, missões culturais e mostras de livros, cinema, música, arte, teatro, entre outras, revelam a importância fundamental dessas instituições na difusão e no fomento de atividades de cooperação cultural entre Argentina e Brasil. Essas atividades envolviam a participação não apenas de políticos e intelectuais vinculados ao Estado, mas, como demonstrado, também de vários setores da sociedade civil, inclusive da iniciativa privada que, em vários momentos, contribuiu na propaganda e com recursos financeiros durante a realização dos diversos projetos culturais entre os dois países.

\section{b) O impulso à aproximação através dos empreendimentos editoriais}

Os governos de Justo e Vargas criaram políticas para a promoção de empreendimentos editoriais entre Argentina e Brasil através da tradução de autores do espanhol e do português. Paralelamente, a efervescência intelectual do período em torno do americanismo estimulou as relações literárias e editoriais entre os dois países. De acordo com Gustavo Sorá (2003: 108), o ano de 1937 emergia 
como o mais fecundo dessas relações, quando foram criadas a Biblioteca de Novelistas Brasileños, da Editorial Claridad, e a Biblioteca Autores Brasileños Traducidos al Castellano, editada pelo Ministerio da Justicia e Instrucción Pública. Ambas marcariam a fundação, em paralelo, dos parâmetros fundamentais para a circulação da cultura escrita nas sociedades nacionais.

Além dessas bibliotecas, que procuravam reunir autores representativos do que se via como a brasilidade e como os maiores problemas políticos e sociais do país, também foram publicados Quijote de los niños, de Monteiro Lobato (1938), e Proceso del Estado Corporativo, de Pedro Motta Lima e José Barbosa de Mello. Na Biblioteca de Obras Famosas foram editados Los Sertones. La tragédia del hombre derrotado por el médio, de Euclides da Cunha (1942, n. 75), e a primeira edição de Vida de Luiz Carlos Prestes. El Caballero de la esperanza (1942, n. 77), biografia escrita por Jorge Amado.

Em outra coleção, a Biblioteca de Grandes Biografias, foram incluídos La vida heroica de Fuana de Arco (1944), escrito por Érico Veríssimo e traduzido por Matilde de Elia Etchegoyen, e Eça de Queiroz: el arquétipo del siglo XIX (1945), de Viana Moog. Na Biblioteca Hombres e Ideas: el pensamento y la acción puestos al servicio de la causa de un mundo mejor, publicou-se a biografia Osvaldo Cruz. El Pasteur del Brasil, vencedor de la febre amarilla, de autoria de Phoción Serpa. Em 1945 também foram editados De la necesidad de ser polígamo, texto de teatro escrito por Silveira Sampaio com tradução de Benjamín Garay, e El padre Anchieta: vida de un apóstol en el Brasil primitivo, de Celso Vieira.

No Brasil, em paralelo a essa política editorial argentina, saiu a Coleção Brasileira de Autores Argentinos. A Comissão Revisora brasileira foi presidida por Pedro Calmon, um historiador tão prestigiado quanto Levene, que dirigiu a Comissão argentina. De acordo com Sorá, no plano das ideias e no plano editorial ambos os conjuntos de livros devem ser compreendidos como espécies oficiais de um gênero de coleção de ensaios de interpretação das realidades nacionais. A coleção brasileira iniciou-se em 1938 e terminou em 1951, totalizando nove volumes traduzidos por J. Paulo de Medeyros.

Os livros traduzidos foram: Síntese da história da civilização argentina, de Ricardo Levene (1938), com prefácio de Pedro Calmon; De Caseros al 11 de setiembre, de Ramón J. Cárcano (1939), com prefácio de João Neves; Orações seletas de Bartolomeu Mitre (1940), com prefácio de Oswaldo Aranha; Bases de fuan B. Alberti (1941), com prefácio de Afrânio Mello Franco; Vidas argentinas, de Octavio Amadeo (1942), com prefácio de Octávio Tarquínio de Souza; Seis figuras do Prata, de Juan P. Echague (1946), com apresentação de E. Tourinho; O santo da espada, de Ricardo Rojas (1948), com prefácio de Augusto F. Schmidt; Mitre, de Rodolfo Rivarola (1950), com prefácio de Álvaro Lins, e Recordações de província, de Sarmiento (1951), com prefácio de Acácio França. 


\section{c) Artes: entrelaçamento de alteridades}

O intercâmbio artístico, que constitui outro capítulo relevante na história das relações culturais entre Brasil e Argentina no período estudado, foi impulsionado, em grande medida, pelos acordos bilaterais no campo cultural. O expressivo fluxo de escultores, pintores, literatos, músicos, atores etc. entre os dois países marcou um momento de descoberta do "outro", até então quase desconhecido.

Ao traçar um panorama da vida e da obra de alguns dos principais pintores brasileiros contemporâneos ${ }^{5}$ que pouco antes haviam exposto seus quadros na Argentina, e considerando a importância deles, o interventor do Museo Nacional de Bellas Artes de Buenos Aires, Jorge Romero Brest, elogiou a iniciativa do diretor do Museo de Bellas Artes de La Plata, o pintor argentino Emilio Pettoruti, pela realização de exposições de obras de 20 desses artistas na sua cidade, entre os dias 2 e 19 de agosto de 1945, e em seguida em Buenos Aires, de 25 de agosto a 7 de setembro.

Brest afirmou que a pintura brasileira era bem distinta da argentina, até em seus aspectos técnicos - o que não se podia estranhar, uma vez que a técnica verdadeira somente era o instrumento da alma -, porque expressava uma realidade diferente, em seus aspectos materiais, de natureza e condição humana, e na sua formação espiritual, por meio do jogo de "influências estranhas". Entretanto, ressaltava:

Hagamos un esfuerzo, pues, los hombres del sur de este continente, los que tenemos raíces hispánicas y una arborescencia italiana, francesa, inglesa o alemana, para comprender con emoción esa realidad indígena, lusitana y negra que comienza a expresarse con facundia feroz en todos los planos de la cultura brasileña. (Brest, 1945: 9)

A concepção de um diálogo curioso e interessado entre duas identidades culturais distintas - a argentina e a brasileira - permeava o espírito da época de maior tolerância e compreensão para com outra sociedade. No campo artístico, essas trocas de experiências foram vistas como positivas, pois contribuiriam para um enriquecimento mútuo, além de possibilitarem ao grande público o acesso a essa outra realidade.

Apesar desse confronto de identidades apontado por Brest, ao afirmar que a pintura brasileira poderia parecer um conjunto de influências estranhas aos olhos dos argentinos, a grande maioria das artes nesse período na América Latina demonstrava preocupação com a questão da identidade nacional e com a temática social. Suas origens remontavam ao Movimento Modernista dos anos 1920. 
Segundo Maria Helena Capelato (2005: 255), no final dessa década, na América Latina, a exemplo do que ocorria na Europa, houve uma crescente politização da cultura, com o retorno à discussão sobre o uso da palavra "vanguarda", expressando a clássica oposição entre a "arte pela arte" e a "arte engajada". Nesse contexto, a maioria dos artistas latino-americanos revelou preocupação com os problemas das suas respectivas sociedades.

A tentativa de recuperação das origens esteve, em geral, associada a uma valorização da cultura popular e de suas tradições. O muralismo mexicano, como representação de uma nova arte social, foi a expressão mais importante dessas mudanças.

Em função de todos esses movimentos que influenciaram o campo das artes, já havia uma expressiva mobilização da classe artística da Argentina e do Brasil com o intuito de promover uma aproximação cultural. Os subsídios governamentais foram fundamentais para a concretização desse propósito. Dessa maneira é que deve ser pensado o papel das artes no intercâmbio entre as duas sociedades, pois, ao mesmo tempo em que atendia aos interesses políticos e econômicos, também fazia parte dos anseios de melhor conhecimento recíproco. Assim, a partir desse momento, o intercâmbio atinge um patamar diferenciado.

\section{d) O pan-americanismo escolar}

O intercâmbio escolar foi um outro aspecto expressivo na aproximação cultural da Argentina e do Brasil, que contou com uma ampla participação de professores e alunos dos dois países. Esse fluxo contínuo, entre os anos 1930 e 50, estimulou a criação de inúmeras delegações, escolas em homenagem a ambos os países, concursos de redação e de poesia, a concessão de bolsas de estudo a fim de desenvolver pesquisas sobre o país vizinho, e até mesmo a implementação de uma proposta pedagógica inovadora, com o objetivo de estimular o sentimento de fraternidade continental nos alunos em relação aos demais países americanos - especialmente entre argentinos e brasileiros.

Tratava-se do pan-americanismo escolar que, tanto na Argentina como no Brasil, havia se iniciado nos anos 1920, através de políticas educacionais. Em 1922, o Consejo Nacional de Educación argentino, através de um decreto, designou as escolas de Buenos Aires com o nome das seguintes repúblicas latino-americanas: Estados Unidos do Brasil, Bolívia, Chile, Colômbia, Cuba, Costa Rica, Dominicana, Equador, Guatemala, Haiti, Honduras, México, Nicarágua, Paraguai, Peru, Panamá, São Salvador, Oriental do Uruguai e Venezuela.

Por meio dessas escolas, o corpo docente e os alunos deveriam promover atividades escolares - como a comemoração de datas cívicas, palestras, exposições, o canto do hino nacional, a confecção de bandeiras nacionais, a recepção de personalidades etc. - que contribuíssem para estreitar os vínculos amistosos 
com as repúblicas irmãs. Tal medida foi bem recebida pela imprensa brasileira, como atesta o artigo "A escola a serviço da paz", da Gazeta de Notícias, de 3 de fevereiro de 1925, que elogiava a resolução do Conselho de Educação argentino como "altamente simpática". O texto ainda acrescentava que a intenção dessa política era preparar as novas gerações em um ambiente mais saturado de ideias de paz e cordialidade internacional.

A construção do edifício da Escola República do Brasil foi muito longa e demorada. Somente em 15 de novembro de 1933 ela foi inaugurada. Depois disso, foram criadas mais oito escolas, com o mesmo nome, em várias províncias argentinas. Uma delas era escola normal. Também foi fundada a Escuela Quintino Bocayuva, em Buenos Aires. Essas escolas existem até hoje, mas pouco mantêm do seu caráter pan-americano. Geralmente, apenas em ocasiões muito especiais, como a independência do país patrono, o ideário de fraternidade americana é relembrado.

No Brasil, o pan-americanismo escolar surge com Carneiro Leão, diretor geral da Instrução Pública do Rio de Janeiro (1922-1926). Ele iniciou uma série de homenagens aos países americanos, dando os seus nomes a 20 escolas. Esperava-se que essas escolas contribuíssem para a criação de um sentimento de união, de solidariedade e de cooperação continental em defesa da liberdade. A administração de Fernando de Azevedo (1927-1930) deu continuidade a essa prática.

Entretanto, assim como o nacionalismo, o pan-americanismo assumiu uma projeção maior na década de 1930, sobretudo na gestão de Anísio Teixeira na Secretaria de Educação do Distrito Federal (1931-1935). As escolas criadas homenagearam os seguintes países latino-americanos: Honduras, México, Nicarágua, Paraguai, Venezuela e Argentina. Atualmente, essas escolas são administradas pela Prefeitura do Rio de Janeiro. Porém, sua proposta pedagógica foi desvinculada do projeto original.

Mesmo interrompendo o seu trabalho, em 1935, quando pediu demissão de seu cargo devido a pressões políticas - estava sendo acusado de participar da revolta comunista liderada por Luis Carlos Prestes -, Anísio Teixeira implantou uma proposta pedagógica inovadora - relacionada ao movimento "escolanovista" - nas escolas fundadas durante a sua gestão, o que contribuiu para o processo de modernização cultural pelo qual passava a capital carioca.

Nesse contexto, merece destaque a Escola Argentina que, além de promover atividades culturais de aproximação com o país vizinho, tornou-se uma das escolas "experimentais" da capital brasileira. Os resultados positivos desse trabalho pedagógico eram constatados nas cartas que os alunos brasileiros escreviam aos argentinos e que foram publicadas na revista produzida pela escola: 
A nossa escola é um pedaço da pátria Argentina (...);(...) pudessem estar presentes à nossa festa para sentirem, mais de perto, o carinho, o amor, a dedicação com que cultuamos os nomes e a data gloriosa do torrão de vocês; (...) que a Argentina e o Brasil sejam um só coração a palpitar, trabalhando pelo progresso e pela paz do mundo. (Chaves, 2007: 162)

Assim, construía-se a imagem do país vizinho como amigo. A criação de um sentimento de amizade, em relação ao Brasil, também foi trabalhado de maneira competente pelas escolas argentinas. No ano de 1952, em uma carta ao governo brasileiro na qual relatava as comemorações na capital portenha em torno da Independência do Brasil, Luzardo anexava a redação de Néstor Oscar Suárez, da $6^{\mathrm{a}}$ série, falando da confraternidade argentino brasileira:

Calificar de fraternales las relaciones entre Brasil y Argentina significa transpuser los limites de la cortesia internacional, para estrecharmos en un abrazo espontáneo, nacido del afecto, que cabija a toda América, porque es América, el milagro que nos ha convertido en hermanos bajo la Cruz del Sur (...). Brasileños y argentinos, tenemos un trabajo común, por él hemos luchado en el pasado, y por él estamos labrando el porvenir. Noble tarea porque de ella aguarda la civilización, el triunfo de la justicia y de la libertad... ${ }^{6}$

Dessa forma, através das escolas "brasileiras" e "argentinas", procurou-se criar um sentimento de fraternidade entre os alunos, professores e demais membros da comunidade escolar em relação ao país vizinho. Contudo, a descontinuidade dessas políticas, em função das constantes oscilações nas relações bilaterais, comprometeu o desenvolvimento dessa prática pedagógica.

\section{e) Intercâmbio intelectual e científico}

A cooperação entre os médicos argentinos e brasileiros foi a mais intensa do período estudado, como mencionado anteriormente. Dessa forma, o intercâmbio entre as Academias Nacionais de Medicina de Buenos Aires e do Rio de Janeiro era um bom exemplo de como essa parceria poderia trazer resultados profícuos para ambas as sociedades. Essa cooperação científica já era tradicional entre os dois países, ocorrendo desde o século XIX. Os graves problemas de saúde pública traziam sérias dificuldades no relacionamento comercial e político de ambos os governos. Por esse motivo, fazia-se necessário encontrar soluções conjuntas para a manutenção de um bom entendimento entre essas economias complementares. Além desse intercâmbio, outras formas de cooperação ocorreram no campo industrial, comercial, educacional e até mesmo militar. ${ }^{7}$ 
No Brasil, essa estrutura de relações culturais interamericanas foi organizada a partir do Itamaraty, do Ministério da Educação e do DIP. O principal veículo de difusão da intelectualidade latino-americana no país foi o "Pensamento da América", suplemento do jornal $A$ Manhã. Essa seção teve uma publicação regular de agosto de 1941 a fevereiro de 1948. Divulgava, em suas páginas, tudo o que fosse relativo ao "espírito pan-americano". Através do suplemento, os leitores brasileiros poderiam ter acesso a artigos sobre literatura, música, história, artes plásticas, política, folclore, dança, geografia e urbanismo. Em suma, toda espécie de atividades culturais provenientes do continente americano.

$\mathrm{Na}$ Argentina, o intercâmbio intercontinental era realizado, principalmente, pela Comisión de Copperación Intelectual, vinculada ao Ministério das Relações Exteriores. Também foi assinada uma série de convênios e acordos culturais com países do continente. Obviamente, tais acordos foram muito maiores e mais amplos com os países de língua espanhola, se os compararmos com os feitos com o Brasil. Contudo, a oposição da maioria da intelectualidade argentina ao projeto cultural peronista criou barreiras ao intercâmbio.

No entanto, vários intelectuais argentinos de renome aderiram ao regime e trouxeram contribuições importantes para conferir legitimidade à sua política cultural. Merece destaque também a expressiva participação de diversos setores da sociedade civil, como professores, estudantes, trabalhadores, cientistas, escritores, juristas, médicos etc.

Os setores da intelectualidade que eram críticos a esses governos tentaram deslegitimar suas ações, tanto na esfera política quanto na cultural, também promovendo o intercâmbio entre os dois países. Um exemplo bem significativo foi o dos intelectuais brasileiros que se exilaram em Buenos Aires devido à repressão do Estado Novo - como Jorge Amado e Monteiro Lobato. Durante sua estadia na capital portenha, aproximaram-se dos intelectuais e do mercado editorial argentino e publicaram suas obras em espanhol.

Do lado argentino, Victoria Ocampo e outros intelectuais contrários ao peronismo usaram a literatura como uma forma de resistência e mantiveram um constante diálogo com a intelectualidade brasileira e de outras partes do continente, conforme atestam as contribuições de Jorge Luis Borges em jornais brasileiros, como o suplemento "Pensamento da América".

\section{f) Intercâmbio sindical como política de aproximação bilateral}

Procurando reforçar a ideologia de seu regime, Perón conferiu um papel novo e importante ao trabalhador: o de adido operário. Dessa forma, esse segmento tornou-se um relevante agente na aproximação política e cultural entre o regime e os demais países do continente. Nesse contexto, cabe assinalar que o justicialismo argentino encontrou expressiva acolhida no trabalhismo brasileiro 
- grande parte das lideranças sindicais, como também o ministro do Trabalho João Goulart, além de outros políticos, intelectuais e grupos da sociedade civil, apoiaram ou participaram diretamente do intercâmbio sindical.

Em 1952, Noticias Gráficas noticiava a viagem de uma delegação da Central de Trabalhadores argentina ao Rio de Janeiro, a fim de participar da Quinta Conferência dos Estados da América da Oficina Internacional do Trabalho (OIT):

La delegación encabezada por el titular de la Central Obre$r a$, señor Fosé G. Espejo, y la integran representantes de diversas entidades sindicales de nuestro país. En calidad de asesores acturán el secretario adjunto de la Confederación General del Trabajo señor Florêncio Soto; Mariano Vergara, de la Federación Argentina de Sindicatos Agrícolas; Hector H. Di Pietro, de la Asociación de Trabajadores de Casas de Renta y fuan Garone, secretario de la delegación. (Noticias Gráficas, 1952: 5)

Membros do Instituto Cultural Argentino-Brasileiro receberam a delegação operária argentina no aeroporto do Galeão, o que demonstra o interesse do instituto na cooperação sindical. Afinal, fomentar o intercâmbio bilateral era sua principal atribuição. Fato relevante também foi o evento em si, que reuniu delegações de todo o continente, destacando o nível de organização sindical do período e a importância da conquista de seu apoio às políticas estatais.

Contudo, a política trabalhista peronista foi veementemente repudiada pelos setores contrários a uma aproximação com a Argentina, que defendiam que a melhor alternativa para o desenvolvimento do Brasil seria ampliar os vínculos com os Estados Unidos. Além disso, tais setores viam com certo temor a possibilidade de uma revolução liderada pelos sindicatos.

\section{Considerações finais}

Finalizando, concluo que o grande e contínuo fluxo de intercâmbios entre Brasil e Argentina no decorrer do período de 1930 a 50, com alguns momentos de refluxo - em decorrência das tensões e conflitos devidos às divergências ideológicas e disputas políticas e econômicas entre os dois países -, promoveu uma grande mobilização de atores estatais e não-estatais, com uma ativa e expressiva participação de vários grupos da sociedade civil. Essas diferentes formas de cooperação cultural contribuíram para a desmistificação do "outro", o argentino ou o brasileiro, que passaram a se compreender melhor, levando ao questionamento o imaginário da rivalidade. 
Além disso, esses projetos estavam associados a interesses políticos e econômicos que concebiam a integração regional como uma estratégia, tanto para ampliar a cooperação entre os países, quanto para promover o maior desenvolvimento e autonomia da América do Sul, consolidando a ideia de criação de um bloco econômico, como ficou expresso na proposta do Pacto ABC.

Dessa forma, comprovo que a análise das relações argentino-brasileiras sob o prisma cultural traz novas interpretações sobre o período de 1930 a 1954, demonstrando que os regimes nacionalistas desses anos, tradicionalmente classificados como autoritários e rivais, também abriram significativo espaço para a cooperação cultural entre suas sociedades, com o intuito de criar as bases de um processo de regionalização sul-americano.

Notas

1. Paradigma dominante que privilegia os aspectos políticos, econômicos e militares nas relações entre os Estados. A preocupação central do realismo é a guerra e a paz. Como consequência, os estudiosos filiados a essa vertente se preocupam fundamentalmente com a questão da manutenção da segurança nacional contra as ameaças militares exteriores. Seu surgimento está relacionado à crise liberal dos anos 1920, mas, para fundamentar as bases do pensamento realista, os seus mentores retrocedem a Tucídides, Maquiavel e Hobbes.

2. Corrente teórica que defende a valorização da dimensão cultural nas relações internacionais, pois, na sua concepção, o poder é constituído, sobretudo, por ideias e contextos culturais. Assim, ideias compartilhadas, das quais se originam as normas, as instituiçõoes, os valores etc., dão significado à distribuição do poder através de percepções ou identidades de interesses. Portanto, a cultura constitui-se num elemento fundamental para a compreensão da realidade.
3. Esta mudança pode ser comprovada pela crescente preocupação com a ampliação e melhor organização do setor cultural do Itamaraty ao longo do período de 1930 a 1950. Essas reformas também refletiram o grande interesse na profissionalização do corpo diplomático, garantindo maior eficiência em sua atuação e, ainda, a ampliação de seu vínculo com a política estatal.

4. Os acordos culturais e convênios tiveram a adesão da Bolívia, Chile, Paraguai e Uruguai.

5. Os trabalhos expostos foram dos seguintes pintores: Tarsila do Amaral, Iberê Camargo, Hilda Campofiorito, Quirino Camporiorito, José Bernardino Cardoso Junior, Rubem Cassa, Lucy Citti Ferreira, Milton Dacosta, Percy Deane, Cícero Dias, Emiliano Di Cavalcanti, Heitor dos Prazeres, Oswaldo Goeldi, Djanira Gomes Pereira, Francisco Rebolo Gonsales, Clovis Graciano, Alberto da Veiga Guignard, Percy Lau, Carlos Leão, Roberto Burle Marx, José Morais, Alcides Rocha Miranda, José Pancetti, José Alves Pedrosa, Cândido Portinari, Tomás Santa 
Rosa Junior, Carlos Scliar, Lasar Segall, Orlando Teruz e Aldari Henriques Toledo.

6. Arquivo Histórico do Itamaraty, anexada à carta de Luzardo a Vargas. Buenos Aires, 11 de setembro de 1952.

\section{Referências bibliográficas}

AZEVEDO, Cecília. Identidades compartilhadas: a identidade nacional em questão. In: ABREU, Marta \& SOIHET, Rachel (orgs.). Ensino de História: conceitos, temáticas e metodologia. Rio de Janeiro: Casa da Palavra, 2003, p. 38-54.

AZEVEDO, Francisca N. \& KNAUSS, Paulo. Imagens de uma aproximação: periódicos literários e a circulação de ideias entre o Brasil e a Argentina nos anos 30. Seminário Brasil-Argentina: a visão do outro. Brasília: Funag, 2000.

BREST, Jorge Romero. La pintura brasileña contemporánea. Buenos Aires: Poseidon, 1945.

CAPELATO, Maria Helena Rolim. Multidões em cena. Propaganda política no varguismo e no peronismo. Campinas, São Paulo: Papirus, 1998.

Modernismo latino-americano e construção de identidades através da pintura. Revista de História. São Paulo, vol. 153, n. 2, 2005, p. 251-282.

CERVO, Amado Luis. Relações internacionais da América Latina: velhos e novos paradigmas. Brasília: Ibri, 2001.

CHAVES, Miriam Waidenfeld. Escola Argentina no Antigo Distrito Federal durante os anos de 1930: um torrão argentino em solo brasileiro. Revista Brasileira de Edu-
7. Em várias cartas de embaixadores e artigos de jornais, encontrei informações sobre visitas de estudantes aos colégios militares e missões de cooperação militar entre Argentina e Brasil.

cação. Rio de Janeiro, vol. 12, n. 35, 2007, p. 253-267.

Diário de Getúlio Vargas. Rio de Janeiro: Fundação Getulio Vargas, vol. 1, 1995.

DEVES VALDÉS, Eduardo. O pensamento nacionalista na América Latina e a reivindicação da identidade econômica (1920-1940). Estudos Históricos, Rio de Janeiro, n. 20, 1997.

GOMES, Ângela de Castro. História e historiadores: a política cultural do Estado Novo. Rio de Janeiro: Fundação Getulio Vargas, 1999.

Capanema e sua correspondência: projeto político e sociabilidade intelectual. In: GOMES, Ângela de Castro (org.). Capanema: o ministro e seu ministério. Rio de Janeiro: Fundação Getulio Vargas, 2000.

FRAGA, Rosendo. La Argentina y Brasil en las primeras décadas del siglo. Seminário Brasil-Argentina: a visão do outro. Brasília: Funag, 2000.

FREYRE, Gilberto. Americanidade e latinidade da América Latina e outros textos afins. Organização Edson Nery da Fonseca. Brasília: EdUnB; São Paulo: Imprensa Oficial do Estado, 2003.

MOURA, Gerson. Autonomia na dependência: a política externa brasileira de 1935 a 1942. Rio de Janeiro: Nova Fronteira, 1980. 
PARADISO, José. Um lugar no mundo: Argentina e a busca de identidade internacional. Rio de Janeiro: Civilização Brasileira, 2005.

PLOTKIN, Mariano. Mañana es San Perón: propaganda, rituais políticos e educação no regime peronista (1946-1955). Buenos Aires: Ariel, 1993.

PORTINARI, Cândido. Sentido social del arte. Cuadernillos de Cultura. Buenos Aires: Centro de Estudiantes de Bellas Artes, 1947.

ROLLAND, Denis (coord.). Histoire culturelle des relations internationales. Paris: L'Harmattan, 2000.

RUSSEL, Roberto \& TOKATLIAN, Juan Gabriel. El lugar de Brasil en la política exterior argentina. Buenos Aires: Fondo de Cultura Económica, 2005.

SALVATORE, Ricardo D. Imágenes de un imperio: Estados Unidos y las formas de representación de América Latina. Buenos Aires: Sudamericana, 2006.

SANTOS, Raquel Paz dos. Uma nova reflexão historiográfica das relações argentino-brasileiras a partir da dimensão cultural (1930-1954). Anuario del Centro de Estudios Históricos Profesor Carlos S. A. Segreti. Córdoba, vol. 7, 2007, p. 409-422.

SORÁ, Gustavo. Traducir el Brasil: una antropología de la circulación internacional de ideas. Buenos Aires: Zorzal, 2003.

VIALE, César. Cuatro años de Presidencia en el Instituto Argentino-Brasileño de Cultura. Buenos Aires: Imprensa Nacional, 1945.

WENDT, Alexander. Anarchy is What States Make of It: The Social Construction of Powers Politics. USA: International Organization, n. 46, Spring 1992.

\section{Resumo}

Este estudo desenvolve uma nova perspectiva das relações Brasil-Argentina a partir da análise de sua dimensão cultural entre os anos 1930-1954. Trata-se de mostrar como uma aproximação entre esses dois países foi incentivada através de projetos de cooperação intelectual, científica e artística, com o objetivo de desfazer imagens negativas e criar um sentimento de fraternidade entre brasileiros e argentinos. Com base na ideia de que uma maior cooperação contribuiria para o fortalecimento da região, e com o objetivo de alcançar uma futura integração econômica, essa prática também foi estimulada entre os demais países da América do Sul.

Palavras-chave: cultura, diplomacia, cooperação, integração regional

\section{Abstract}

This study proposes a new perspective on the relations between Argentina and Brazil, focusing on the analysis of their cultural dimension between 1930 and 1954. It tries to show how the approximation between the two countries was encouraged by projects of intellectual, scientific and artistic cooperation, aiming to erase negative images and create a feeling of brotherhood between 
Brazilians and Argentinians. The same practice has been stimulated in other South American countries, with the idea that cooperation would strengthen the region and assure a future economic integration.

Key words: culture, diplomacy, cooperation, regional integration

\section{Résumé}

Cette étude propose une nouvelle perspective sur les relations

Brésil-Argentine à partir de l'analyse de leur dimension culturelle entre les années 1930 et 1954 . Il veut montrer comment, à travers des projets de coopération intellectuelle, scientifique et artistique, un rapprochement entre les deux pays a été encouragé dans le but d'effacer les images négatives et de créer un sentiment de fraternité entre Brésiliens et Argentins. Ce type de pratique fut également stimulé entre les autres pays d'Amérique du Sud, à partir de l'idée qu'une plus forte coopération pourrait contribuer à fortifier la région et à en assurer la future intégration économique.

Mots-clés: culture, diplomatie, coopération, intégration régionale 